\title{
FINANCIAL PLANNING - PLANNING FOR THE FUTURE
}

Ramachandran T.S.*

Planning is a process of bridging the gap between where you are and where you want to be.

Financial planning is a process of setting financial objectives and having a road map to reach these objectives. It is planning for the future.

Every individual is required to be clear about his financial objectives and the road map to reach the same, irrespective of his financial status and his age, for the simple reason that it is better to have one, than not having one. The necessity of money in one's life and the security, both physiological and psychological, that money provides cannot be underplayed.

Given this, the article proceeds to describe various financial stages of a common man and provides a broad sketch of how one can achieve his financial objectives, given the space limitations.

Plenty of literature is available on financial planning. Hence, what is required to be learnt more than finance knowledge or options is financial discipline, because financial planning is more of common sense and simple arithmetic.

Every individual undergoes broadly three stages in his earning career, namely i) Early career stage ii) Mid career stage and iii) End career stage.

*Associate Professor, Christ College Institute of Management, Bangalore 
We need to understand that, at each stage, our financial priorities or financial commitments are different and our earning capacity and the ability to save are also different. Apart from this, the ability to take risks i.e. financial risks also differs from person to person.

Risk is always meant in the negative sense. Risk means the probability of not getting what you thought you would get or for what you had planned for. The chance of losing the money you had invested or the chance of not getting interest payments regularly from where you had invested or the chance of ending up in litigation in a property you had invested in. God forbid, but these are the risks one would face everyday in life. One type of risk is an assumed risk, that is, knowingly investing in risky proposals, like a risky business or equities. The other is ending up in problems one did not know of, while the investment decision was taken.

It is also common sense that, for a common man, the ability to take financial risk is lesses as time progresses.

This is the broad framework within which one aims to draw one's financial plan and also reach the plan by the time one reaches superannuation.

Financial planning does not guarantee wealth. It aims to avoid surprises.

Financial planning is all about allocation of assets; how much to put where?

Before doing the allocation, do you know how much your estimate of the annual expenses is?

Your annual expenses can be broken into monthly, quarterly, half yearly and yearly expenses. More often we leave out the half yearly and yearly expenses and try to squeeze them in when those expenses occur. It would be a great idea to draw up a universe of all the expenses you are likely to incur in a year and break it up into periods mentioned above, namely, monthly, quarterly, half-yearly and yearly. This would clearly give you an idea of your cash flows, particularly your expenses occurring at different points of time in a year.

Remember, these are only annual expenses. Obviously, the other major expenses which are not included in this exercise are the capital expenses, namely for one's 'Home Sweet Home', the furniture and white goods, Vehicle (two wheeler or four wheeler), children's higher education and marriage and the most important, our own period of retirement. These capital expenses probably occur in the same priority sequence for many of us. 
Apart from these costs, we also have a hidden cost which is inflation. Defined in simple terms, inflation is the increase in the cost of goods we use for our household purposes, year after year.

Our financial priorities at different stages of our career / life are different, starting from buying furniture for the house, white goods, two wheeler, computer, mobile phone, etc. and moving towards bigger investments like a car or a home. Also, the priorities at our mid career stage would be to take care of the children and their needs.

Towards the end of our career our priorities shift towards providing higher education for our children, getting them married and our own superannuation.

Given this understanding of our broad spectrum of life stages and the demands on finance at different stages of life, what would be the appropriate way to meet these objectives comfortably?

Like one of those Murphy's laws, the first thing to keep in mind about savings is that, if there is a provision to withdraw a part or full of your savings before it matures, in all probability, you would withdraw, irrespective of the genuineness for such withdrawal. So the chances of you completing such savings as originally envisaged by you, for a particular purpose, are very less.

Accepting such financial discipline (or indiscipline) as common, the only way to proceed is to save for a really long term, with the least ability to break your savings.

A few options are here:

Save the maximum through the employee provident fund and public provident fund. Inclusive of the tax benefit, the returns are attractive.

Buying a land with the aim of constructing a home or for selling at a later date would be a good decision. But this has to be done with care. Two things which are to be kept in mind are that, the land must be situated at a place which has potential for growth and not just anywhere. The land must be devoid of any possible litigation in future.

Invest in equity markets through good financial advisors, through systematic investment plans, for a really long term. This requires more financial discipline than the other two suggested above, as you can break the investment any time you want and secondly, the volatility of equity markets in the short term or medium term is likely to deter you from investing in the equity market. 
All of the above investments have the ability to beat inflation and appreciate to give returns which can meet your financial objectives comfortably by the time you retire. And for long term investors, these are not risky investments.

As for those who do not want to consider the above, believing it to be risky, believe in the power of compounding and save early, regularly and for long enough to beat the inflation and pray that you would.

Happy financial planning 